\title{
Making News at The New York Times
}

\author{
Nikki Usher \\ School of Media and Public Affairs, George Washington University \\ nusher@gwu.edu
}

Nikki Usher's Making News at the New York Times (Ann Arbor: University of Michigan Press, 2014) is an academic page-turner of sorts, offering unique insight into one the world's most renowned quality newspapers. The writing is clear and vigorous, and she offers intriguing analyses of digital shifts in the field that are still taking place even now. For six months in 2010, Usher observed the multitasking, interaction, and negotiation of changing routines and procedures that went on in this famed newsroom, and the conclusions she is able to draw from this unprecedented access are surprising. She suggests that a different kind of news values are now having a huge impact upon the basic structure of news production and presentation, and as well as upon journalism as labor.

Ethnographic narratives may not reveal either insight or excellence in prose and seldom reveal both, but Usher's are a happy exception. Her goal for the project anticipates the intriguing findings to follow-to "provide an inside portrait of the Times that shows how journalists attempted to negotiate the challenges of creating online and print content according to emergent journalism values: immediacy, interactivity and participation" (Usher 2014:4). Insight into how news is discussed, rated, and prioritized at the daily news desk is rare even in the context of smaller newspapers, but Usher exposes, to an extent, the New York Times itself, supplying observations from internal meetings and detailed descriptions of journalists as they cope with the ever-increasing pace of the news today. The strength of this book, that is, resides in these unique glimpses of everyday activity at one of the world's most important newspapers, where we see that historical pedigree in fact supplies little relief from the growing demands of digital production.

Usher wrangled her access to the paper after being lucky enough to meet the right people at the right time, and she was able to "work with New York Times lawyers to hammer out an agreement" on the conditions that she not leak either

The Journal of Media Innovations 1.2 (2014): 129-131.

(C) Maria Theresa Konow-Lund 2014

http://www.journals.uio.no/index.php/TJMI 
breaking news or internal news development and business strategies. This is a regrettable concession, of course, that flies in the face of media transparency in the digital age. Usher worked around it by agreeing to delimit herself to business news production, though her methodological chapter does not clearly explain how such a delimitation satisfied the lawyers as such. Such a focus makes the title of her book slightly misleading, but in truth, the insight she gains from the business news department translates to other news areas as well. The three business journalists she shadowed all worked differently, so she was able to draw upon a range of news rhythms, multitasking abilities, and speeds to link her businessnews study to overall news production as well.

Three following chapters are devoted to immediacy, interactivity, and participation, respectively, which she identifies as the central news values of the digital age. The arrival of 24/7 coverage, or what Usher calls "ASAP news," is the single most profound paradigm shift at the newspaper, touching upon all three values. It propels, among other things, a comprehensive reconsideration of the allocation of resources, so that the circumstances of journalistic production follow from the priority of immediacy, rather than the other way around. The demands of ASAP news cannot be satisfied by tools alone (as several media organizations have hoped) but require fundamental changes to journalism as practice (and to the recruitment of those who would practice it), as well as the institution's financial model and strategy. One might even wish for more from Usher about all of the implications here, particularly regarding the ways in which ASAP news privileges the perpetual (if creative) repurposing of existing online material rather than the development of new material and especially the cultivation of exclusivity. After all this has historically and traditionally been part of the uniqueness of The New York Times. Usher simply wonders, "How will the newspaper retain its authoritative curation powers if it must respond to the ASAP pressure? This remained a lingering challenge - and opportunity - for the newspaper during the time of my research." While Usher touches upon the constraints of chasing immediacy, she supplies only limited evidence of journalists' regrets in this regard - not being able to do in-depth sourcing, for example-and this pattern holds true for her discussions of interactivity and participation as well, though she presents both in a balanced fashion nevertheless. In these three chapters, she elaborates upon the consequences of immediacy, interactivity, and participation on news production but provides little contextual analysis of how new and traditional clash as journalists work within different media (text, sound, photograph, video, TV). Usher manages to look to the horizon of news production, but she does not reconcile her predictions with all that has gone before. For example, she discusses the production of video in her chapter on interactivity, relating it to the importance of engaging the audience and make them stay with the newspaper's online site. But she does not complement her analyses with insight from the huge number of previous studies on TV and audience engagement. Such a strategy would have given her more perspective upon the way journalists (presenters) prepare for a television performance-she 
sees this preparation as manipulation, but it has always been this way. Throughout the history of broadcasting, part of the production of the news involves coaching reporters and presenters regarding how to behave in front of camera and communicate the already researched facts in the most successful fashion. Though there is a conflict here between the cultivated spontaneity of the newspaper and the demands of visual delivery, it is not a new conflict, as the history of either medium bears out. Interested readers would also certainly welcome a more overarching discussion about the balance that must be struck between professional content and user contributions, especially from a larger historical perspective.

The convictions of New York Times management regarding the changing business conditions for news production and presentation in the digital age became public in May 2014 via an internal but leaked report that found its way online (http://mashable.com/2014/05/16/full-new-york-times-innovation-report). In tandem with Usher's book, this report supplies a very full impression of the Times at present but begs the question yet again of what has changed, and how, in relation to such a storied institutional past.

However, despite these few objections, Nikki Usher certainly fulfils her goal of painting a very full portrait of a profound moment in this news organization's history. The field of news ethnography would be poorer without this valuable contribution.

Maria Theresa Konow-Lund

Associate Professor

Department of Journalism and Media Studies, Oslo and Akershus University College of Applied Sciences 